\title{
Drömmen om vår plats $i$ universum
}

\author{
ERIK TÄNGERSTAD
}

Alla talar om Europa, men vad är det för Europa som alla talar om? Ibland låter det som om Europa var namnet på något slags storslaget projekt, medan det andra gånger tycks handla om en monumental tradition. Men oftast verkar Europa vara namnet på en välkänd och självklar plats, även om platsens gränser inte är alldeles oomstridda. Går vi till ordböcker och encyklopedier för att skapa klarhet i denna begreppsliga villervalla kan vi efter en stunds bläddrande konstatera att Europa är en svårbestämbar term. Ändå fortsätter den eviga diskussionen att producera det ena påståendet om Europa efter det andra, utan att någon verkar tycka det vara mödan värt att fråga efter om vad debatten egentligen handlar. Därför frågar jag än en gång vad det är för något vi alla talar om, när vi talar om Europa.

Oavsett vilken uppslagsbok vi väljer så är det första vi möter under sökordet "Europa" en mer eller mindre omfattande bestämning av en geografisk plats. Vi har, som det verkar, att göra med en ort. Men platsen är inte endast rumslig; under sökordet finner vi helt säkert en redogörelse för Europas historia, och den delen av uppslagstexten är lika säkert något längre än den om Europas geografi. För lika givet som att Europa är en plats, lika självklart är det att Europa är en historia. Ändå förefaller det som om vi i vardagslag intalar oss att Europa är en plats som har en historia. Kanske blottar vi här ett omedvetet drag i vårt sätt att tänka. Pröva på lek att kasta om bestämningarna: Europa har en plats som är en historia. Plötsligt låter "Europa“ som namnet på en inkräktare, en utifrån kommande ockupant som tagit oss alla 
här, och tillika vår gemensamma historia i beslag. Denna oväntade kontrastverkan utmanar otvivelaktigt vår världsbild. Är det möjligen så att vi rankar det rumsliga högre än det tidsliga, så att geografin på något sätt tycks stå över och bortom historien? Kanske finns här en ledtråd i vårt fortsatta sökande efter vad det är vi talar om.

Bergfast, brukar man säga om något som inte låter sig ändras. Men om storheter som t ex Europa är historier så är det bra mycket svårare att distansera sig från det temporala i dessa beteckningar än om de har historier. Och denna bristande distans skänker en svampig känsla som är allt annat än bergfast.

Ibland kan vi få höra påståenden som „New York är världens mest europeiska stad“, eller "Neapel är'den enda stad i tredje världen som inte har något europeiskt kvarter". Åt sådant är det svårt att inte le. Några kanske ler överseende inför den typen av, som det till en början verkar, oupplysta påståenden. Men de flesta av oss, tror jag, ler förvånat över att oväntat ställts inför något som låter paradoxalt utan att vara det. Om Europa överhuvud taget skulle kunna sägas beteckna något alls, så vore det namnet på en tillfällig sammanflätning $i$ tid och rum mellan geografi och historia. Vi har inte att göra med någon fast fixerad punkt, vare sig i tiden eller i rummet. Ifall någon allvarligt påpekar att Neapel ligger i Europa medan New York inte gör det, då kan vi kosta på oss ett överseende leende.

I dynamiken mellan det vi uppfattar som tid och rum uppstår det vi försöker att greppa, det vi försöker nagla fast med hjälp av begrepp. Under våra ständiga försök kommer begreppen att ändras; kanske skärpas och utvecklas, men i vart fall ändras. Här är det alltså på sin plats att ställa oss frågan: Vad är det vi talar om då vi talar om begreppet „Europa“?

Europa är västerlandet; Occidenten; das Abendland. Europa är landet där solen går ned: skymningslandet. Europa avgränsas i öster mot landet där solen går upp; das Morgenland; Orienten; kort sagt: Asien. Står vi mitt i världen så kan vi under loppet av en dag klart konstatera att solen går upp i Österlandet och ned i Västerlandet. Världens mitt borde då ligga öster om Europa men väster om Asien. Men när vi ger oss ut på jakt efter platsen kom- 


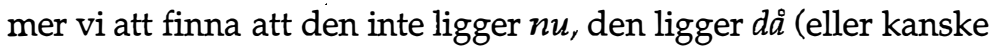
låg). Platsen är i lika hög grad historisk som geografisk; den är begreppslig, kort sagt.

För cirka 2700 år sedan avgränsade Homeros i en hymn sitt eget land från det Europa som ligger i väster. Därigenom gjorde han det gamla assyriska begreppet till sitt eget. För på assyriska skiljer man asu-landet, där solen går upp, från ereb-landet, där den går ned. Det märkliga är nu bara det att Homeros lyckades flytta världens mitt västerut. Från assyrisk horisont borde han befunnit sig i ereb-landet, men han säger ju själv att Europa ligger därborta i väster. Från Homeros har världen fătt ett nytt centrum. Som goda européer känner vi naturligtvis till denna historia, som är vår egen. Andra människor har givit oss vårt namn, „europé", och vi har tacksamt tagit emot det och iklätt oss det. Vi har fătt "Europa" och gjort det begreppet till vårt hem; vi är nu hemmastadda i begreppet. Eller hur?

Vi lever alla i samma begreppsliga ordning; en ordning vi konceptualiserat genom benämningen "verkligheten". Att lämna „verkligheten“ är en omöjlighet, säger vi oss. Och de tragiska gestalter som ändå ger sig på sådana dödfödda projekt kallar vi „eskapister". Vi gör oss på så sätt ständigt till våra egna fångar i vår egen begreppsliga, eller om man så vill diskursiva, ordning. Och i diskursen ,,verkligheten "ligger vårt hem: begreppet "Europa”. Vi har funnit vår plats i universum, tror vi.

För som goda européer känner vi till att solen inte kretsar kring oss. Det är istället vår planet, ,jorden", som kretsar kring solen, vilken i sin tur kretsar kring "vintergatans" axel, och den i sin tur rör sig bland de övriga galaxerna i den oändliga rymden. $V i$ vet att vi befinner oss $i$ universums periferi, och inte vid dess centrum. Det har vi lärt av Kopernikus.

Kopernikus tanke är magnifik. Vill vi förstå planeternas skenbart märkliga rörelser så räcker det inte med att bara observera och läsa de klassiska skrifterna, utan vi måste även tänka nydanande och självständigt. Vi måste bryta upp den rådande tankeordningen genom att kritisera den inifrån, hitta dess inre motsägelser och reorganisera den. Om vi ställer oss på solen, istället för att stå på jorden och titta ut i rymden, hur ser då stjärnhimlen ut? 
Naturligtvis kan vi inte fysiskt genomföra denna omplacering, men vi kan leka med tanken. Vi tänker oss ett nytt perspektiv och en ny horisont. Och då inträffar någonting vi aldrig kan låta våra sinnen verifiera, någonting vi endast genom rationell argumentation kan övertygas att tro på. Och när vi tror då tror vi att vi vet. Utifrån vår diskursivt strukturerade plats i universum tror vi oss ha identifierat rymden. Då säger vi oss att vi vet hủr vår plats $i$ universum är konstituerad.

Samtidigt glömmer vi det vi tog till utgångspunkt. Vi har glömt det diskursiva $i$ vår bestämning av var vi tror att vi befinner oss. Vi har glömt att vi fastställer vår position med hjälp av solens upp- och nedgång. Vi har glömt att Asien är Orienten och att vi själva bor i solnedgångens land, den plats som benämns "Europa“. Kort sagt, vi är inte där vi trodde att vi var, vi är någon annanstans. Och ändå intalar vi oss att vi nu bättre än någonsin tidigare vet just var vi befinner oss. Här uppstår en spänning i den diskursiva ordning som vi försöker inreda till vårt hem. Vore det inte ett störande av hemfriden skulle vi kunna ge röst åt en av Niètzsches frågor: „Alltsedan Kopèrnikus verkar människan ha hamnat på ett sluttande plan — numera rullar hon allt fortare bort från medelpunkten - varthän? in i intet?" Men att ta upp denna fråga vid middagsbordet är direkt opassande. Det skulle innebära ett aktiverande av den diskursiva ordningens latenta inre spänning. Istället intalar vi oss att vi vet var vi är och vart vi är på väg. Vi tror verkligen att vi vet!

Men vad är det vi tror oss veta? Hur ska vi.kunna veta att vi verkligen vet det vi tror oss veta? Egentligen var det enklare när vi trodde på Gud. Då var Gud alltings skapare, samt förnuftets och kunskapens garant. Men sedan vi européer gjort oss av med Gud saknar vårt vetande garanti. Hur ska vi nu kunna veta att det vi uppfattar med våra sinnen verkligen korrekt återger skapelsen sådan den nu en gång för alla är given oss av... av..?

Det brutala svaret är att vi inte kan det. Och det svaret gav oss Kant: „Tidigare antog man att all vår kunskap måste rätta sig efter föremålen; men alla försök att utröna något om dem a priori genom begrepp, på så sätt att vår kunskap skulle utvidgas, omintetgjordes under denna förutsättning. Man må då en gång våga 
försöket huruvida vi inte kommer längre i de metafysiska uppgifterna, om vi antar att föremålen måste rätta sig efter vår kunskap", skriver han i inledningen till Kritik av det rena förnuftet. Vi ser alltså inte det som är, utan det våra ögon tillåter oss att se. Jag kan inte varsebli "tinget i sig", utan endast det "tinget för mig" som mina sinnen kan registrera. Att sinnenas konstitution och vårt sätt att tänka bestämmer vår bild av verkligheten, istället för att verkligheten rakt av medieras via våra sinnen och vårt tänkande till att inuti våra medvetanden bli någon slags perfekt återspegling av någon slags realitet, brukar kallas „den kopernikanska vändningen" i Kants filosofi. För liksom Kopernikus tänkte Kant annorlunda. Även han kunde rikta en immanent kritik mot den rådande diskursiva ordningen. Och inte heller Kants tankegång låter sig verifieras av sinnesintrycken.

Liksom Kopernikus genomför Kant ett resonemang som inifrån tidigare föreställningar förklarar mer än tidigare föreställningar gjort. Istället för att vi, enligt det gamla sättet att tänka, skulle kunna observera och begreppsligt resonera oss fram till hur skapelsen egentligen är beskaffad, så ändrade Kant nu perspektivet så att världen, sådan den framträder för människan, blir objektet för undersökningen. Och därefter undersöker han vidare hur vi som människor under denna förutsättning bäst ska leva våra liv. Hur ska vi människor kunna befria oss från traditionernas och begreppens bojor och realisera friheten i det rena betraktandet? Efter Kant menar vi oss kunna själva använda vårt eget förnuft till att kritisera och korrigera gamla, oegentliga fördomar. Detta kallar vi framsteg. Vi befinner oss i en framåtriktad rörelse i vilken vi går från klarhet till klarhet. Upplysningen skiner oss allt starkare i ansiktet. Ännu är vi inte upplysta, men vi befinner oss i en tid av upplysning, som Kant själv har uttryckt det. Med progressivt självmedvetna steg går vi rätt in i den gryende framtiden på vår väg hemåt.

Hemåt, mot vår egentliga destination, mot vårt hem i universum. Glömska om vår utgångspunkt, döva för olyckskorparna och bländande av upplysningen går vi allt längre in i det okända. Men vi, ja just vi moderna européer, intalar oss att vi är på väg hemåt. 
För Kant tror verkligen att vi kan komma „längre i de metafysiska uppgifterna", dvs att vi i en transcendent rörelse ska kunna överskrida begreppen, befria oss från de falska bländverken och nå fram till vår autentiska bestämmelse. Här finns en tro på vetandet, en tro på identifierandet av det som bortom begreppens bojor verkligen är. Här härskar drömmen om att vi i framtiden ska kunna veta.

Så när vi talar om Europa så talar vi inifrån drömmen att kunna identifiera vår verkliga plats bortom all begreppslighet. Och i så fall är allt tal utifrån begreppet „Europa“ snarast ett utopiskt försök att transcendera oss till vår autentiska plats i universum; just ett försök att komma hem.

Men redan här stöter Kants kritik på en inifrån kommande kritik. För om vi ingenting kan veta om det famösa ",tinget i sig", hur kan vi då påstå att det är ett ting? Hur kan vi tala om det vi inte vet, och inte kan veta, något om? Hur ska vi kunna överskrida begreppen när intuitionen förträngs och hela vårt tänkande strävar mot förnuftig begreppslighet? Hur kan vi föregripa framstegen och redan nu förespegla oss vår destination? Det kritiska ifrågasättandet av kritiken har mötts med kompakt tystnad. För vem vill säga att vi inte bara kommit vilse och inte längre vet var vi är, utan dessutom tappat bort oss själva på vägen och inte ens vet vilka vi själva är.

Se där har vi moderna européer vårt predikament. Vi vet varken var vi befinner oss, eller vilka vi är. Vi talar och talar och producerar det ena påståendet efter det andra. Vi talar om „Europa”, om något som vi intalar oss är en plats, vår egentliga plats, bortom begreppen, trots att det står klart för alla' och en var att „Europa“ är ett begrepp. Vi talar om „Europa“ i ett försök att komma till det „europeiska huset", i en ansträngning att komma till vårt hem i universum där vi får vara oss själva. Men allt vårt prat för oss endast längre och längre bort från den plats vilken vi tror oss ha identifierat. Det vill säga under förutsättning att man nu kan tala om att man rör sig allt längre bort från en plats som kanske aldrig existerat.

Ur detta perspektiv är vår färd oroväckande tragisk, men ännu så länge kan vi intala oss själva att vi utgör historiens avant- 
garde som lägger framsteg efter framsteg bakom oss på vår väg mot upplysningens förlovade land. För ännu kan vi säga oss att förnuftet lyser upp vår väg, även om det är ett förnuft som fungerar annorlunda än vi först trodde. Och då är det för tidigt att förkasta upplysningen som ideal och utopi.

Kanske bryter ändå den inifrån kommande kritiken av kritiken av kritiken en ny väg. Kanske står vi nu efter Kopernikus och Kant inför en tredje kopernikansk vändning. Slappna av och tänk på lek att tron på transcendensen var ett misshugg, en ansats som ledde i rakt motsatt riktning mot den förväntade och önskade. Pröva tanken att vi lever i och genom begrepp. Det finns inget "därbortom" begreppen. „Vi“" är vårt eget begrepp på oss själva. "Jag", liksom "verkligheten" är diskursiva ordningar, vilka producerats diskursivt. Naturligtvis måste vi tro att vi har någon slags gemensam grund på vilken all denna begreppslighet vilar, annars skulle ju kommunikationen bryta samman. Men vi kan inte, och kommer heller aldrig att kunna, konceptualisera denna gemensamma grund. Det enda begripliga vi kan säga om den "verklighet", som vi måste anta ligger bortom det begreppsliga, är att den är "overklig", det vill säga att den endast kan antas vara bortom det diskursiva. Vår värld är begriplig just därför att den är begreppslig. Vi kan möta en diskursiv ordning genom att inifrån ställa upp en kritiserande diskursiv ordning, men vi kommer aldrig någonsin att kunna bekämpa ett gammalt begreppsligt system genom att sätt upp ett nytt; konkurrerande. Europa kan aldrig bekämpas genom upprättandet av ett annat Europa. Det moderna kan aldrig övervinnas av något slags utifrån kommande postmodernitet, utan det postmoderna (vad det nu skulle kunna vara) springer fram ur modernitetens egna inre motsägelser. Förnuftet kommer aldrig att kunna hotas av något slags antiförnuft, utan varje kritik av förnuftet måste vara förnuftig för att kunna kommuniceras. Ingen kommer någonsin att kunna dra sig undan politiken genom proklamerandet av något slags apolitiskt reservat. För vi befinner oss inuti diskursens ordning och kan endast inifrån bedriva diskursiv kritik, vilken i sin förlängning alltid är politiskt laddad. Det enda sätt på vilket vi skulle, om vi ville, kunna bekämpa en diskursiv ordning vore att aktivera ord- 
ningens egna inneboende paradoxer och anomalier. Och antagligen bör jag här använda citationstecken runt „inifrån”, eftersom det är poänglöst att tala om något „utifrån”, vilket ju underminerar begreppsparet „inne - ute”. Den enda formen av politisk radikalitet, tror jag, går under benämningen dekonstruktion. Och kanske är den tappre soldaten Svejk, i all sin underminerande motsägelsefullhet, den politiska radikalitetens främste symbolfigur.

Inte många, gissar jag, blir nu speciellt bragta ur fattningen av det ovanstående. Det jag under benämningen en „tredje kopernikansk vändning" försökt redogöra för är knappast något annat än det som vanligen kallas "the linguistic turn”, det vill säga den allt mer utbredda vändningen mot språkfilosfi bland olika vetenskapsdiscipliner.

Men, kanske nu någon invänder, betyder inte detta att vi givit upp varje möjlighet till politisk påverkan? Innebär inte detta resonemang att vi frånsäger oss all förmåga att påverka vår situation? Ja och nej. Ja, om vi tror att vi med politiska medel skulle kunna påverka och ändra sådana situationer som vi intalat oss vara utomdiskursiva. Nej, för bortsett från perspektivförskjutningen från en transcendental befrielse av mänskligheten till en diskursiv mänsklighet har ingenting nytt inträffat. Lösenordet här är historien.

Betänk det tidigare påståendet att Europa inte har någon historia; Europa är historia. Historien är inte vår tillgång, historien är vår konstitution. Förhållandet är detsamma som i fältbiologernas slagord: „Skogen är inte något hem för växterna och djuren, det är växterna och djuren som är skogen!" Ingen historiker kan gör anspråk på att skriva historien "wie es eigentlisch gewesen" helt enkelt därför att vi alla befinner oss nedsänkta i historien, utan möjlighet att finna några fasta referenspunkter mot vilka vi skulle kunna mäta detta märkliga fenomen: historien. Vi står alltid distanslösa inför historien och denna distanslöshet skapar, som sagt, en svampig känsla som är långt ifrån bergfast.

Men om vi nu inte kan finna några externa referenspunkter eller måttstockar mot vilka vi kan mäta upp historiens egentlighet; om inte ens sådana begrepp som „verklighet”, "sanning”, "au- 
tenticitet", „Europa“, „vi“", eller ens "jag" står utanför den diskursiva ordningen, det vill säga historien: Vad kan vi då göra? Vad bör vi då göra?

Vi kan läsa om källorna. Vi bör reflektera över vår situation. Inte för att vi är tvingade till det, annat än av det diskursiva tvång vi ständigt lever mittuppi, utan för att vi i reflektionen har en möjlighet att just aktivera den diskursiva ordningens egna inneboende motsättningar. Det är i och genom reflektionen som vi har vår möjlighet att påverka vår situation, det är här vi kan agera politiskt.

För i denna svampiga känsla av en förvirrande distanslöshet inför den ogripbara, men ständigt påtagliga historien finns just här ändå något påtagligt: texten. Den text som låter sig läsas är vår möjlighet till reflektion, och det är i förhållande till den vi kan handla. Texten ligger där, framför oss, obegriplig; ja, den motstår oss. Begriplig blir den inte förrän vi läser den. Och då låter vi begripligheten i sin tur styra vår läsning. För att vi ska nå fram till något meningsfullt underkastar vi oss läsningens styrning, en styrning som i sin tur är avhängig av vårt krav på begriplighet. Men detta krav på begriplighet står inte i något självklart förhållande till texten vi läser. Det är därför samma text kan uppfattas helt olika av olika läsare. Läsaren är i första hand underkastad läsningens styrning, och endast $i$ andra hand textens. Detta är värt att hålla i minnet vid alla diskussioner om politiskt agerande.

Här är det på sin plats att ta upp protestens form, för kanske har jag nu lyckats provocera fram en protest. Kanske säger du som läsare till mig som författare: "Det 'vi' du sluddrar om rör mig inte i ryggen. Du kanske ser dig som 'en modern europé', men jag är det inte! Jag är inte 'vi' med dig!" Och den protesten vore lika legitim som begriplig. Man kan läsa det hittills skrivna som ett försök att konstituera en gemenskap mellan oss läsare, mellan alla oss som tillsammans utgör ett "vi". Om jag som författare försökte tvinga in dig i detta "vi" genom någon slags omnipotent skrivning av typen: "Vi moderna européer är alla lika inför varandra, ja mer än så, vi är alla ett med varandra", så skulle det ligga nära till hands att du som läsare skulle känna dig 
kringränd. Och ur denna känsla skulle en vilja till protest kunna spira. Du skulle kunna läsa fram en distans gentemot textens "vi": vi skulle då inte vara "vi" med varandra. I denna distanseringsprocess uppstår olika poler med vilka olika läsare skulle kunna identifiera sig och varandra. Genom protest och distansering skulle en slags negativ form av identifiering uppstå: "Jag är minsann inte någon 'modern europé'!" Och i förlängningen skulle en vilja till positiv identifiering uppträda: "Jag vet vem och vad jag är! Jag är svensk!"

Men här uppstår en komplikation kring protestens form, för vad är det som läsaren protesterar mot? Texten, eller sin lüsupplevelse av texten? Och vad händer om läsaren identifierar texten med den egna läsupplevelsen? En påtaglig konsekvens av en sådan sammanblandning vore att läsaren då uppfattar sig protesterande mot något som kommer "utifrån", det vill säga från den påtvingade texten, något som läsaren måste försvara sig mot. Men om protestens form pekar mot en protest av läsupplevelsen, snarare än en mot texten, om alltså läsaren uppfattar sin protest som något som härstammar "utifrån", trots att protesten snarast riktas mot något "inifrån" kommande, nämligen den egna läsupplevelsen, vad händer då? I bästa fall blir man som läsare alltmer känslig för den stora skillnaden mellan texten å ena sidan, och läsupplevelsen å den andra. För det är i denna skillnad man kan läsa fram en protest mot den egna läsupplevelsen. I sämsta fall inträffar en blockering i vilken man fullständigt låter text och läsupplevelse sammanfalla till en enda stor, hotande enhet mot vilken man med alla medel måste försvara sig. Och så länkas främlingsskräcken och främligsfientligheten samman.

„Europa” är ett begrepp vars betydelse ständigt skiftar. „Europa" är ett ord som låter sig läsas på många olika sätt. Att försöka definiera „Europa" är som att försöka fånga en solkatt, eller som att en gång för alla, sist och slutligen, fixera sin egen identitet.

Jag tror att vi moderna européer, och till oss räknar jag alla som har något europeiskt språk som modersmål, står inför en politisk konfrontation; en konfrontation som rör vårt sätt att identifiera oss själva, universum och vår plats i universum. Skiljelinjen 
kan dras mellan två olika grundåskådningar: å ena sidan mellan de som tror att vi på det stora hela behärskar vår sitution; de som säger: „Vi vet!" (med den underliggande betydelsen: „Vi tror att vi vet"). Å andra sidan finns de principiella tvivlarna; de som säger: „Vi tror!" (med den underliggande betydelsen: „Vi vet att vi tror"). Människor från båda dessa grundåskådningar talar om „Europa" som en framtida dröm, antingen om ett „Europa" i vilket den goda utopin förverkligas, eller, tvärt om, används „Europa" som etikett på det ständigt ofullgångna projektet; som en slags utopi som går ut på att utopier inte låter sig förverkligas. Konfrontationen mellan dessa två grundåskådningar kommer, fruktar jag, att bli våldsam. Och dess utgång är på intet sätt given.

Alla talar om Europa, och de.flesta gör det som om de sökte en plats. Ändå tycks det stå alltmer klart att det här inte finns någon plats, inte något hem i universum, annat än begreppet. Vi är begripliga därför att vi är begreppsliga, och vi befinner oss ständigt „inuti“ begreppsliga ordningar. Vi identifierar oss i och genom begrepp.

Trots detta verkar de flesta ta för givet att begreppen är något slags medium med vars hjälp det går att transcendera sig till någon slags "egentlig" realitet bortom begreppen. Även de som i vetenskapsteoretiska sammanhang varmt talar för något slags "linguistic turn" förskjuter sin position då det handlar om den tillämpade vardagspolitiken, en poltik som (ifall den nu inte helt och hållet förträngs) uppfattas i termer av „empirisk" och „verklig", eller åtminstone "trovärdig" och "realistisk".

Här finns en motsägelse inom den diskursiva ordningen „Europa", en motsägelse som inte endast framträder som en rad olika, varandra motsägande, visioner om hur begreppet „Europa" bör tydas, utan som allt tydligare framskymtar i skillnaden mellan dem som å ena sidan tror att det går att nå realiteten bortom begreppen och dem som inte tror det. Och om vi då inte kan nå fram till någon kunskap om det som antas vara realiteten bortom begreppen, då vet vi inte längre var vi är eller vart vi är på väg. Då vet vi heller intelängre vilka vi är. Då befinner sig hela vår världsbild i kris. Vad gör vi då? Slår tillbaka i något slags 
spastiskt ryck? Det kan tyvärr vara på sin plats att varna för ett Europa som mardröm.

Europa som dröm eller som mardröm, här fordras ställningstaganden och politiska handlingar för att befrämja det positiva och motverka det negativa. För egen del menar jag att det gäller att ständigt motverka villfarelsen att vi människor någonsin skulle kunna transcendera oss till någon antagen plats bortom begreppen. Vår plats i universum är diskursiv. Det är detta påstående som jag ovan argumenterat för, trots att det är ett påstående jag inte kan bevisa. Min motivation är övertygelsen att om vi identifierar oss med detta påstå̀ende så kan kanske de samhälleliga konvulsionerna bli mindre omfattande än vad jag fruktar att de kommer att bli. 